\title{
PRE-TERM PRE-LABOUR RUPTURE OF MEMBRANES AND THE ROLE OF AMNIOCENTESIS
}

\author{
${ }^{1.2}$ ANNA P KENYON, ${ }^{1,2}$ KHALIL N ABI-NADER AND ${ }^{2}$ PRANAV P PANDYA \\ 'Elizabeth Garrett Anderson Institute for Women's Health, University College London, 86-96 Chenies Mews, \\ London WCIE 6NX. ${ }^{2}$ Fetal Medicine Unit, University College London Hospitals NHS Foundation Trust, 235 \\ Euston Rd, London NWI 2BU.
}

\section{INTRODUCTION}

Pre-labour premature rupture of membranes (PPROM) is defined as rupture of membranes more than 1 hour prior to the onset of labour at $<37$ weeks gestation. PPROM occurs in approximately $3 \%$ of pregnancies and is responsible for a third of all preterm births. ${ }^{1}$ Once membranes are ruptured prolonging the pregnancy has no maternal physical advantage but fetal morbidity and mortality are improved daily at early gestations: $19 \%$ of those infants born $<25$ weeks develop cerebral palsy (CP) and $28 \%$ have severe motor disability. ${ }^{2}$ Those infants born extremely pre term $\mid<28$ weeks) cost the public sector $\$ 75835$ (95\% CI £27906-145508) per live birth ${ }^{3}$ not to mention the emotional cost to the family. To prolong gestation is therefore the suggested goal: however how and why might we delay birth in those at risk?

PPROM is one scenario associated with preterm birth and here we discuss the causative mechanisms, sequelae, latency, strategies to prolong gestation (antibiotics) and consider the role of amniocentesis. We will also discuss novel therapies.

\section{PATHOPHYSIOLOGY OF MEMBRANE RUPTURE}

The membranes, which act to protect and isolate the fetus, are composed of two layers. The inner layer (amnion) which connects after fusion in the late first trimester, to the outer layer (chorion leave) through a collagen-rich vascular zone. These membranes are directly apposed to the maternal decidua.

The high resilience of the preterm fetal membranes makes them strong enough to withstand strong non-penetrating forces. ${ }^{4}$ The supra-cervical portion of the membranes has been proposed as the site where the process of weakening and rupture through collagen remodelling ${ }^{5}$ may be initiated. ${ }^{6}$ Collagen remodelling is executed through the activation of the collagen specific matrix metalloproteinases (MMPs) 
in the extracellular matrix of the amniochorionic membrane. This remodelling may be due in large part to inflammation which may be infection related. ${ }^{7,8}$ The supracervical location (i.e. close to the vaginal flora) of the structural changes observed in membranes prior and after rupture has supported the proposition that even in term pregnancies infection is implicated. Microbial invasion of the amniotic cavity is seen in $18 \%$ of term labours and $30 \%$ of term rupture of the membranes (ROM). ${ }^{9}$ However, pre-labour ROM (as distinct from labour with intact membranes) has a greater association with infection.

\section{Consequences of membrane rupture}

In comparison to term ROM the rate of positive bacterial culture at the time of PPROM in the absence of labour is approximately $25-40 \% .{ }^{1}$ One-2\% of pregnancies with PPROM have clinical chorioamnionitis at presentation with $3-8 \%$ developing subsequent chorioamnionitis. ${ }^{1}$ Maternal infection increases the risk of neonatal infection ${ }^{9}$ and the risk of infection clinically detectable in either mother or baby increases with duration of PPROM. A Nigerian study in 2007 of 356 women attending a University hospital with PPROM $<36$ weeks (1994-2003) reported 20\% of patients delivered within 24 hours with $71 \%$ delivered between the $2^{\text {nd }}$ and $10^{\text {th }}$ day. The majority of women $(29.7 \%)$ were $28-30$ weeks gestation. All women received prophylactic antibiotics and steroids if $<34$ weeks gestation. Twenty nine per cent had evidence of chorioamnionitis of whom $70 \%$ had had multiple vaginal examinations (a known risk factor for infection). Thirty eight per cent of those with chorioamnionitis had received antibiotics within 24 hours of membrane rupture. Those delivering within 48 hours were least likely to have chorioamnionitis. ${ }^{11}$ While this study was at an institution within a developing nation with higher perinatal morbidity and mortality than western studies the report demonstrates clearly the risk of infection over time in the context of PPROM using current management strategies. When considering management of PPROM risk of infection is thus the single most important determinant of maternal and fetal morbidity and mortality and increases with duration of ROM.

\section{LATENCY IN PPROM}

Pasquier et a ${ }^{12}$ reviewed all cases of PPROM at $24-33+6$ weeks gestation (542 women) at their French institution between April 1999-2001 and reported that 60\% will deliver spontaneously during the first week of PPROM, with $80 \%$ delivering within 3 weeks. Cotton et $\mathrm{al}^{13}$ reported a latency of $3.6 \pm 2$ days (range 0.5-9 days) in 19 women with PPROM with $52.6 \%$ delivering within 72 hours of admission. Manuck et $\mathrm{al}^{14}$ confirmed that latency following PPROM at 22-33.9 weeks gestation was 8 days (interquartile range $3-15$ days). 
Predictive factors within the PPROM group to determine which cases have the shortest latency have been reported. Fisher et $\mathrm{al}^{15}$ suggested that cervical length when measured translabially is not predictive of latency, chorioamnionitis or postpartum endometritis. However a Korean prospective study performed transabdominal amniocentesis, sampled maternal blood for white cell count (WCC) and C reactive protein (CRP) and measured cervical length in 50 singleton pregnancies $<36$ weeks with PPROM. Patients with positive amniotic fluid cultures had significantly shorter cervical length and higher WCC and CRP than those with negative cultures. The prevalence of positive culture was $26 \%(13 / 50)$ and the mean gestational age at amniocentesis was 31.4 weeks. Using a ROC curve the best cut off value of cervical length for identification of microbial invasion of the amniotic cavity was $28 \mathrm{~mm}$ with a sensitivity of $85 \%$ and a specificity of $65 \% .{ }^{16}$ The latency from PPROM to delivery is not reported but the authors cite several other studies with microbial invasion and shorter latency from ROM to delivery in PPROM and infer that a short cervix would therefore be associated with an earlier delivery. The quantity of remaining fluid may be predictive of latency. Parks et $\mathrm{al}^{17}$ studied 129 women with spontaneous PPROM at $<35$ weeks in whom $29 \%$ had an AFI $<5 \mathrm{~cm}$. This level of fluid was associated with higher rates of positive fluid cultures and a shorter PPROM to delivery interval. Both cervical length and anhydramnios may be surrogate markers; of infection, with infection being the main determinant of latency. A recent study by Manuck et $\mathrm{al}^{14}$ has suggested that latency per se is not a risk factor for adverse perinatal outcome but congenital sepsis is (OR 13.2 95\% CI 3.9-44.5). ${ }^{14}$ Thus with expectant management the data suggest that a high proportion of women will deliver spontaneously within a week but the risk of infection increases with duration of PPROM and it is the presence of infection that is clinically important with respect to outcome.

\section{ANTIBIOTICS IN PPROM}

Antibiotic use has been shown to prolong pregnancy in the context of ROM. ${ }^{18}$ However, increasing gestation with antibiotics does not translate into long-term benefits for the offspring. The ORACLE I trial ${ }^{19}$ assessed the benefit of erythromycin and or amoxicillin/clavulinate and placebo for women with PPROM and no signs of infection. While erythromycin was associated with prolongation of pregnancy and reductions in neonatal morbidity, by the age of 7 years there was no difference in the degree of functional impairment amongst children who received antibiotics compared to those who did not. ${ }^{19}$

In the context of intact membranes and no signs of infection, antibiotics may increase neonatal mortality when used in women in preterm labour. ${ }^{20}$ Most recently this was reported in the second ORACLE 7 year follow up study. Women with preterm labour and intact membranes were randomised to the use of erythromycin and/or amoxicillin/clavulinate or placebo. Eythromycin use was associated with an increase in functional impairment in the offspring compared to those not receiving 
erythromycin. Either antibiotic was associated with more cerebral palsy than in women receiving no antibiotics. The number needed to harm in the erythromycin group was 64 (95\% CI 37-209) and in the co-amoxiclav group 79 (42-591). ${ }^{21}$ These studies highlight that in women at significant risk of preterm birth use of antibiotics has not been shown to have benefit ${ }^{21}$ though they may prolong pregnancy. In the context of PPROM therefore, measures to prolong pregnancy must be considered not only in terms of increasing gestation but must translate into measurable long term improvements in outcome for the neonate. Once evidence of clinical infection is apparent delivery should be expedited and should be treated with antibiotics because clinical chorioamnionitis remains an important cause of maternal, fetal and neonatal death. ${ }^{19}$

\section{ROLE OF AMNIOCENTESIS IN PPROM}

\section{Amniocentesis to detect fetal lung maturity}

Given the delicate balance between risks of infection to mother and baby in PPROM with expectant management and the benefit of increasing gestation in the absence of infection (particularly at early gestations), one role of amniocentesis in PPROM would be to determine fetal lung maturity. If confirmed, delivery could be expedited rather than waiting for clinical infection to develop. In 1979, the previously cited Garite study also used their amniotic fluid samples, obtained by amniocentesis in 69 patients with PPROM at 28 to 35 weeks of gestation, to test for lung maturity using the lecithin sphingomyelin LS ratio. ${ }^{22}$

Cotton et a ${ }^{13}$ studied 61 patients with PPROM at 27-36 week's gestation. Liquor was sampled transvaginally if seen to be pooling or by transabdominal amniocentesis. Specimens were then sent for LS ratio and the presence of phosphatidyl glycerol, gram stain and culture were also performed. Delivery was expedited if the LS ratio was mature, or if bacteria were identified on gram stain. Antibiotics were only given in cases of chorioamnionitis. Forty two amniocenteses were performed of which 7 also had vaginally acquired samples. Although the abdominal samples were of greater volume, the results from the two sampling methods were not different. All patients with bacteria on gram stain or culture subsequently developed chorioamnionitis. Twenty six patients had a mature LS ratio (greater than or equal to 1.8). The mean gestational age estimated by the obstetric team in these women was $32.3 \pm 2$ weeks. Subsequent paediatric assessment suggested a mean gestational age of $33.2 \pm 2.2$ weeks. Three of 26 were believed to be 33 weeks by the obstetrician and 36 weeks by the paediatrician. Where the LS ratio was mature, 23/26 women were delivered within 48 hours and the remaining women were delivered by 96 hours. Four infants delivered $<32$ weeks had a mature LS ratios and their neonatal stays were 23, 29, 46 and 83 days. The authors concluded that at less than 32 weeks gestation amniocentesis need not be employed because the overall neonatal morbidity is sufficiently high in 
this group, even in the presence of a mature LS ratio, that management should be conservative. At 34 weeks neonatal morbidity is sufficiently reduced that delivery should be considered. Thus between 32-34 weeks amniocentesis to assess fetal lung maturity may have a role. ${ }^{13}$ Of note, in this study, corticosteroid administration for fetal lung maturity was at the discretion of the attending physician. The discussion explains that steroids were not given in sufficient numbers to determine their efficacy. Whether the increased neonatal morbidity at $<32$ would have been reduced by routine administration of steroids remains to be determined.

Several different methods have since been reported for assessing fetal lung maturity eg TDx FLM II, phosphatidyl glycerol (PG) and lamellar body count (LBC). ${ }^{23}$ These methods are comprehensively reviewed by Grenache and Gronowksi. ${ }^{23}$ LS ratio while still performed by many laboratories has a good sensitivity but lacks specificity. Phosphatidyl glycerol is a late marker of fetal lung maturity. TDx FLM II is a commercially available assay measuring the surfactant to albumin ratio by fluorescence polarization. The test is the most commonly used quantitative method for determining fetal lung maturity and has good sensitivities (95.7-100\%) with specificities of $70-84 \% .{ }^{23}$ Lamellar body count also functions well as a test of fetal lung maturity with sensitivities approaching $100 \%$ and specificities $54-100 \% .{ }^{23}$ The authors conclude that while these tests perform well to determine maturity they are poor predictors of immaturity and that given the increasing prevalence of respiratory distress with reducing gestational age, risk stratified with regard to gestational age might be a more useful tool. ${ }^{23}$ Thus in the context of PPROM a mature result using a rapid test (TDx FLM II or LBC) is strongly predictive of the absence of RDS. Inconclusive results may require additional testing.

\section{Amniocentesis to identify bacterial infection}

The overall rate of positive amniotic fluid culture in patients with PPROM ranges from $25-40 \%{ }^{24}$ Averbach et $\mathrm{al}^{24}$ performed an amniocentesis in 90 consecutive patients with PPROM at 23-36 weeks gestation for microbial culture, gram stain and white cell count. Thirty six percent had positive cultures (e.g. ureaplasma urealyticum, escherichia coli, proteus mirabilis and coagulase negative staphylococcus) but in total $66 \%$ had evidence of infection (culture, gram stain and/or elevated WCC). The clinical characteristics of the women were not different. The mean gestational age at delivery in patients with intra-uterine infection was $31.0 \pm 3.8$ weeks, compared to $33.0 \pm 3.6$ weeks in patients without intra-uterine infection. Birth weight and Apgar score at 1 minute were significantly lower in neonates born to mothers with intra-uterine infection when compared to those without infection. ${ }^{24}$ In 1979, Garite and colleagues ${ }^{22}$ obtained amniotic fluid samples by amniocentesis in 69 patients with PPROM at 28 to 35 weeks and tested lung maturity and screened for evidence of intra-amniotic infection using gram stain, WCC, and culture for aerobic and anaerobic bacteria. ${ }^{22}$ Nine cases had a positive amniotic fluid culture, of which seven developed clinically significant amnionitis, a significant neonatal infection, 
post-partum endometritis or a combination of these. ${ }^{22}$ The other two patients delivered within 24 hours. Of the 21 patients with negative amniotic fluid culture only one developed chorioamnionitis. This study provided preliminary evidence that the presence of intra-amniotic infection defines a subgroup of patients at a higher risk for perinatal complications.

Microorganisms can gain access to the uterine cavity ascending through the vagina and cervix, by haematogenous dissemination through the placenta, by accidental introduction at the time of invasive procedures or retrograde spread through the fallopian tubes. Microorganisms are recognised by pattern recognition receptors e.g. toll like receptors which release inflammatory cytokines and chemokines (e.g. interleukin (IL) 8, IL-1beta and tumour necrosis factor alpha (TNF- $\alpha$ ). Microbial endotoxins and proinflammatory cytokines stimulate prostaglandins (PG) other inflammatory mediators and matrix degrading enzymes. Prostaglandins stimulate uterine contractility whereas degradation of extracellular matrix in the fetal membranes leads to PPROM ${ }^{25}$ Infection then results in a fetal inflammatory response syndrome (FIRS), which may or may not be associated with a maternal inflammatory response. Once bacterial colonisation and maternal systemic response is established fetal and maternal outcomes are much worse. Therefore to identify intramniotic inflammation and/or infection prior to the onset of maternal symptoms of sepsis may be beneficial in terms of neonatal outcome.

Pathologic examination has been the gold standard for the diagnosis of inflammation. However, chemotactic signals must be present for the white blood cells to migrate to the site of injury or infection. Thus, there is a window of time in which a "molecular signature of inflammation" is present before histological evidence is observed. ${ }^{9}$ Thus inflammation is a spectrum and the absence of a maternal fever, chills, rigors and leucocytosis does not exclude a bacterial insult and inflammation. ${ }^{9}$ Romero et $\mathrm{al}^{26}$ have shown that exposure to intra-amniotic inflammation and evidence of a systemic fetal inflammatory response (funisitis) are strong and independent risk factors for the subsequent development of cerebral palsy.

It has therefore been suggested that amniocenteses following membrane rupture may allow early identification of colonisation of the amniotic cavity with bacteria and fetal inflammation and thus provide a window prior to clinically detectable sepsis or bacterial culture when intervention may be beneficial.

\section{Amniocentesis to detect novel markers of inflammation in the amniotic fluid}

\section{Cytokines}

In 1993, Romero and colleagues ${ }^{27}$ assessed the performance of amniotic fluid gram stain, WCC, the inflammatory cytokine IL-6, and glucose levels in detecting the presence of microbial invasion of the amniotic cavity as defined by a positive bacterial culture. ${ }^{27}$ In this study, the prevalence of positive amniotic fluid cultures in 110 


\begin{tabular}{|c|c|c|c|c|c|}
\hline Group & $\begin{array}{l}\text { Depiction } \\
\text { of group }\end{array}$ & $\begin{array}{l}\text { No. of } \\
\text { patients }\end{array}$ & $\begin{array}{c}\text { Procedure- } \\
\text { todelivery } \\
\text { interval (median } \\
\text { and range, days) }\end{array}$ & $\begin{array}{l}\text { Prevalence of } \\
\text { positive amniotic } \\
\text { fluid culture (\%) }\end{array}$ & $\begin{array}{c}\text { Matemal } \\
\text { plasma IL-6 } \\
\text { (median and } \\
\text { range, } p g / m L)\end{array}$ \\
\hline $\begin{array}{l}\text { Group A } \\
\text { Amniotic fluid IL-6 } \leq 7.9 \mathrm{ng} / \mathrm{mL} \\
\text { Fetal plasma IL-6 } \leq 11 \mathrm{pg} / \mathrm{mL}\end{array}$ & & $14(46.6 \%)$ & $5(0.2-33.6)$ & $4 / 14(29 \%)$ & $4.8(3.8-16.8)$ \\
\hline $\begin{array}{l}\text { Group B } \\
\text { Amniotic fluid IL-6 }>7.9 \mathrm{ng} / \mathrm{mL} \\
\text { Fetal plasma IL } 6 \leq 11 \mathrm{pg} / \mathrm{mL}\end{array}$ & & $5(16.7 \%)$ & $7(1.5-32)$ & $3 / 5(60 \%)$ & $7.5(4.2-12.2)$ \\
\hline $\begin{array}{l}\text { Group C } \\
\text { Amniotic fluid IL-6 }>7.9 \mathrm{ng} / \mathrm{mL} \\
\text { Fetal plasma IL-6 }>11 \mathrm{pg} / \mathrm{mL}\end{array}$ & & $6(20 \%)$ & $1.2(0.25-2)$ & $6 / 6(100 \%)$ & $4.4(3.4-45.2)$ \\
\hline $\begin{array}{l}\text { Group D } \\
\text { Amniotic fluid IL-6 } \leq 7.9 \mathrm{ng} / \mathrm{mL} \\
\text { Fetal plasma IL-6 }>11 \mathrm{pg} / \mathrm{mL}\end{array}$ & & $5(16.7 \%)$ & $0.75(0.13-1)$ & $4 / 5(80 \%)$ & $4.8(3.2-18.3)$ \\
\hline
\end{tabular}

b

\begin{tabular}{|c|c|c|c|c|c|}
\hline Group & $\begin{array}{l}\text { Depiction } \\
\text { of group }\end{array}$ & No. & $\begin{array}{c}\text { Severe } \\
\text { neonatal } \\
\text { morbidity (\%) }\end{array}$ & $\begin{array}{c}\text { Gestational } \\
\text { age at delivery } \\
(w k, \text { mean } \pm S D)\end{array}$ & $\begin{array}{c}\text { Amniotic } \\
\text { fluid IL-6 } \\
(\text { ng } / m L, \text { median, } \\
\text { range })(n=59)\end{array}$ \\
\hline $\begin{array}{l}\text { Group } 1 \\
\text { Negative amniotic fluid culture } \\
\text { Fetal plasma IL- } 6 \leq 11 \mathrm{pg} / \mathrm{mL}\end{array}$ & & 27 & $7(25.9 \%)$ & $32.1 \pm 3.1$ & $1.2(0.1-60.7)$ \\
\hline $\begin{array}{l}\text { Group } 2 \\
\quad \text { Positive amniotic fluid culture } \\
\text { Fetal plasma IL- } 6 \leq 11 \mathrm{pg} / \mathrm{mL}\end{array}$ & & 10 & $4(40 \%)$ & $31.9 \pm 2.3$ & $2.0(0.08-19.8)$ \\
\hline $\begin{array}{l}\text { Group } 3 \\
\text { Negative amniotic fluid culture } \\
\text { Fetal plasma IL- } 6>11 \mathrm{pg} / \mathrm{mL}\end{array}$ & & 10 & $6(60 \%)$ & $30.1 \pm 4.9$ & $22.0(0.5-99.5)$ \\
\hline $\begin{array}{l}\text { Group } 4 \\
\quad \text { Positive amniotic fluid culture } \\
\text { Fetal plasma IL-6 }>11 \mathrm{pg} / \mathrm{mL}\end{array}$ & & 26 & $22(84.6 \%)$ & $29.3 \pm 2.9$ & $36.7(0.5-92.8)$ \\
\hline
\end{tabular}

Figure I. Tables reporting inflammation as measured by IL6 concentrations in amniotic fluid and fetal cord blood with respect to bacterial colonisation and neonatal morbidity (a) Classification and procedure-todelivery interval of patients according to amniotic fluid and fetal plasma IL-6 concentrations. (Reproduced from Romero R, et a ${ }^{28}$ with permission.) (b) Severe neonatal morbidity according to presence of microbial invasion of amniotic cavity and fetal plasma IL-6 concentration in 73 patients delivered within 7 days of amniocentesis or cordocentesis. (Reproduced from Gomez R, et al ${ }^{29}$ with permission).

patients with preterm premature rupture of membranes was $38 \%$. Amniotic fluid IL-6 levels were the most sensitive test $(80.9 \%)$ for the detection of microbial invasion of the amniotic cavity while the most specific test was the Gram stain of amniotic fluid $(98.5 \%)$. When cultures were positive the amniocentesis-to-delivery interval was shorter and the neonatal complication rate was higher. In 1998, the same group linked amniotic fluid inflammation to a fetal systemic inflammatory syndrome (FIRS). To do this, they performed concurrent amniocentesis and cordocentesis in 30 patients with PPROM at around 30 weeks of gestation. ${ }^{28}$ Microbial invasion of the amniotic cavity was present in $58.5 \%$ of the patients. Fetuses with plasma IL- 6 concentrations $>11$ $\mathrm{pg} / \mathrm{mL}$ had a significantly higher rate of spontaneous preterm delivery within 48 and 72 hours of the procedure than those with fetal plasma IL-6 levels $<11 \mathrm{pg} / \mathrm{mL}$ (Figure 1). 
In addition, fetuses with plasma IL- 6 concentrations $>11 \mathrm{pg} / \mathrm{mL}$ had a significantly higher rate of severe neonatal morbidity than did those with fetal plasma IL-6 levels $<11 \mathrm{pg} / \mathrm{mL}$ as evidenced in an accompanying study (Figure $1 \mathrm{~b}$ ). ${ }^{29}$

The data presented in Figure 1a suggests that most of the complications occur in the subset of patients with evidence of an intra-amniotic infection/inflammation as defined by amniotic fluid IL-6 level $>7.9 \mathrm{ng} / \mathrm{ml}$ or a positive amniotic fluid culture. There remains a subset of patients with FIRS (fetal plasma IL- $6>11 \mathrm{pg} / \mathrm{ml}$ ) where amniotic fluid cultures are negative and amniotic fluid IL-6 levels are less than $7.9 \mathrm{ng} / \mathrm{ml}$. This subset could represent early haematogenous infectious spread to the fetus or a false-negative amniotic fluid result. These fetuses remain at risk of imminent delivery and poor neonatal outcome but cannot (according to the above criteria) be identified without fetal blood sampling. For this reason, the authors, in subsequent publications, suggest a lower threshold for the definition of intra-amniotic inflammation. Using a threshold of $2.6 \mathrm{ng} / \mathrm{ml}$ for amniotic fluid IL-6, intra-amniotic inflammation was twice as common as intra-amniotic infection /defined by a positive culture) and could identify infection with a sensitivity of $90 \%$ and a specificity of around $75-80 \% .^{30}$

Buhimschi et $\mathrm{a}^{31}$ have shown that proteomic mapping of the amniotic fluid reveals a profile, designated as the Mass Restricted score that is highly characteristic of intraamniotic inflammation. The authors have shown that the presence of four protein biomarkers (neutrophil defensins- 2 and -1 and calgranulins $\mathrm{C}$ and $\mathrm{A}$ ) is highly predictive of preterm birth, funisitis (a hallmark of fetal inflammatory syndrome) and early neonatal sepsis. Of 158 women having amniocentesis to exclude infection in the context of PPROM, histological chorioamnionitis was found in $64 \%$. The Mass Restricted score significantly correlated with stages of histological chorioamnionitis $(\mathrm{r}=0.539, \mathrm{P}<.001)$, grades of choriodeciduitis $(\mathrm{r}=0.465, \mathrm{P}<.001)$, and amnionitis $(\mathrm{r}=$ $0.536, \mathrm{P}<.001)$. The authors concluded that proteomic analysis of amniotic fluid may provide an opportunity for early recognition of histological chorioamnionitis and may in the future identify candidates for antenatal therapeutic interventions. Proteomic mapping of markers is still a research tool but may represent a useful and sensitive clinical adjunct in the future. ${ }^{31}$

\section{Matrix Metalloproteinase Enzymes}

As the matrix metalloproteinase (MMP) enzymes are involved in parturition, premature rupture of the membranes, and intra-amniotic infection, ${ }^{32,34}$ these have also been used to diagnose intra-amniotic inflammation in PPROM cases. Of the various MMPs, MMP-8 has received most clinical attention. In a study assessing the ability of amniotic fluid MMP-8 to detect intra-amniotic infection and inflammation as defined by a positive amniotic fluid culture and amniotic fluid IL-6 levels greater than $2.6 \mathrm{ng} / \mathrm{ml}$, a positive amniotic fluid MMP-8 test result (defined as greater than $20 \mathrm{ng} / \mathrm{ml}$ ) had a sensitivity of $90 \%$, specificity of $80 \%$, positive predictive value of $77 \%$, and negative predictive value of $92 \%$ in the identification of intra-amniotic 


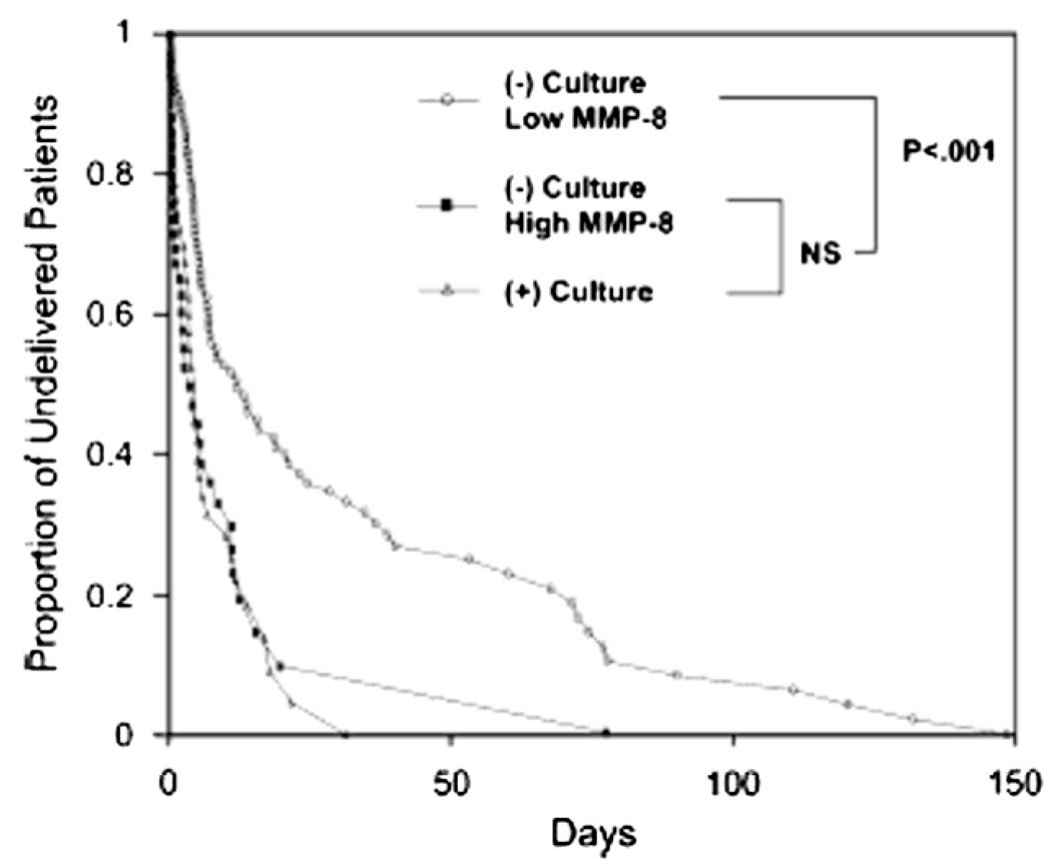

Figure 2. Amniocentesis-to-delivery interval, according to the results of amniotic fluid culture and amniotic fluid matrix metalloproteinase 8 (MMP-8) concentrations in 219 women with pre term premature rupture of membranes. (Reproduced from Shim SS et $\mathrm{al}^{37}$ with permission).

infection. ${ }^{35}$ In this study, a positive MMP- 8 was also an independent predictor of interval to delivery and significant neonatal morbidity. ${ }^{35}$

The major advantage of MMP- 8 testing is that it is available as a bedside test (MMP8 PTD Check (SK Pharma, Kyunggi-do, Korea) requiring 20 ul of amniotic fluid and 15 minutes to obtain results without the need for laboratory equipment. ${ }^{36}$ In contrast, amniotic fluid culture for microbiologic testing requires around 48 hours while the IL-6 assay uses a commercially available enzyme-linked immunosorbent assay ( $\mathrm{R}$ and D systems, Minneapolis, USA) which, although much faster than culture, still needs to be performed in a laboratory setting.

In a more recent study, Shim et $\mathrm{al}^{37}$ studied the clinical significance of positive amniotic fluid MMP-8 (intra-amniotic inflammation) as compared to amniotic fluid culture (intra-amniotic infection). Patients with intra-amniotic inflammation or infection had a shorter interval to delivery (figure 2) and more complications including higher rates of preterm delivery, histologic chorioamnionitis, funisitis, low Apgar scores and admission to neonatal intensive care unit as well as more significant neonatal morbidity and lower gestational age at birth and birth weight. These complications were still statistically significant after accounting for gestational age at amniocentesis. ${ }^{37}$ 
There were no differences in the interval to delivery (Figure 2) or rate of complications between patients with intra-amniotic inflammation and a negative amniotic fluid culture and patients with proven amniotic fluid infection. ${ }^{37}$ These data indicate that intra-amniotic inflammation is a risk-factor for adverse neonatal and maternal outcome as well as for impending preterm delivery irrespective of amniotic fluid culture results. The proportion of amniotic fluid samples where inflammation is observed in the absence of positive culture results could be partially explained by the presence of atypical organisms such as Ureaplasma urealyticum since up to $40 \%$ of these infections are missed using conventional cultures. ${ }^{38}$

The thresholds and criteria used for the definition of intra-amniotic inflammation are variable despite most studies being performed by a limited number of associated researchers. The task of interpreting the results and applying them clinically is formidable.

\section{Technique of amniocentesis in PPROM}

Amniocentesis in PPROM should be done by an experienced operator. In many cases, the reduced amount of amniotic fluid means that access to a fluid pocket is limited to a narrow window. Garite et $\mathrm{al}^{22}$ suggested it might be only technically successful in $51 \%$ of the cases. A 22 gauge needle is most appropriate and the use of a small volume syringe may help prevent blockage due to suction of the nearby the membranes. A trans-amniotic approach is preferable but a trans-placental approach could be used as long as the target pocket does not lie under the central portion of an anterior placenta. ${ }^{39}$ In cases where no intra-amniotic infection or inflammation is evident at amniotic fluid analysis and the decision is made to continue with the pregnancy, repeat amniocentesis in 1-2 weeks may be useful. This is justified by certain authors, as there is evidence that in PPROM the incidence of intra-amniotic infection increases with longer latency periods. ${ }^{40}$

Complications with late amniocentesis are rare. In 137 patients with PPROM examined at 28-34 weeks of gestation, Yeast et a $1^{41}$ reported that amniocentesis was successful in $66.4 \%$. They could not attribute any maternal or neonatal morbidity to the amniocentesis itself and the amniocentesis-delivery analysis suggested that the amniocentesis did not accelerate delivery. ${ }^{41}$ The volume of fluid available for sampling is a consideration. Cotton et $\mathrm{al}^{13}$ performed the procedure only in those with a pool of at least $1 \times 1 \mathrm{~cm} \cdot{ }^{13}$ Frequently only $1-2 \mathrm{ml}$ of fluid were sampled ${ }^{13}$ but this was sufficient for gram stain, culture and LS ratio. Of note Gramellini et $\mathrm{al}^{42}$ showed that after genetic amniocentesis the amniotic fluid index decreases by about $1 \mathrm{~cm}$. The amount of amniotic fluid needed for inflammation/infection studies depends on the studies being performed but in general just a few millilitres. 


\section{Patient acceptability of amniocentesis in PPROM}

There remains the issue of patient acceptability. It should be made clear to the parents that there remains a lot of uncertainty especially regarding long-term outcomes. Despite these difficulties, it is exciting to know that $70 \%$ of patients with PPROM between 28 and 34 weeks would agree to participate in a randomized study comparing expectant management with amniocentesis-based management. ${ }^{43}$ More importantly, those who responded that they would not participate related their refusal to concerns about the complications of amniocentesis such as fetal trauma, iatrogenic preterm labour, infection or pain.

\section{POTENTIAL ADJUNCTIVE THERAPIES IN PPROM: IMMUNOMODULATORS}

In cases of intra-uterine inflammation or infection, the relatively mature fetus may be best delivered. Conversely those fetuses below 32 weeks of gestation may be candidates for in utero treatment. Intra-amniotic infection is rarely eradicated using antibiotics. ${ }^{44}$ Antibiotics with adjunctive therapy might be best studied in those cases where there is intra-amniotic inflammation in the absence of a positive culture or gram stain. Porecco et $\mathrm{al}^{39}$ retrospectively evaluated a policy of induction of labour where intra-amniotic inflammation or infection was evident on amniocentesis, the group managed according to amniocentesis results fared better than the conventionally managed group in regard to composite neonatal morbidity with an average latency period of around 1 week in both groups. ${ }^{39}$ However, the optimal timing of delivery in the presence of intra-amniotic infection or inflammation is still unknown.

Since most of the damage in intra-uterine infection is caused by inflammation mediated by cytokines ${ }^{45}$ a combination of antibiotic and antiinflammatory/immunomodulatory agents may prove to be effective in preventing fetal injury and prolonging gestation. In a primate model of intra-uterine infection using group B streptococci, the addition of indomethacin and dexamethasone to the antibiotic regimen was effective in eradicating the infection, suppressing the inflammatory response and prolonging gestation. ${ }^{46}$ In human neonatal sepsis, use of steroids, ${ }^{47}$ intravenous immunoglobulins, ${ }^{48}$ and colony stimulating factors ${ }^{49}$ were not effective in improving outcomes. Pentoxyphylline, which inhibits the production of TNF- $\alpha$, was effective in reducing the levels of the pro-inflammatory cytokines TNF- $\alpha$ and IL- 6 in premature infants with sepsis. Most importantly it reduced the mortality rate in these infants by about $80 \% .{ }^{50,51}$

\section{CONCLUSION}

There is a need for a randomised controlled trial of amniocentesis-guided management (for the presence of bacteria and lung maturity) versus standard conservative management of PPROM. Until this data is available there may be a role for 
amniocentesis in PPROM at early gestations e.g. $<32$ weeks in selected cases when the risk of delivery may outweigh the risks of remaining in utero. This is particularly pertinent following the ORACLE trial when the benefits of antibiotics to prolong gestation has been called into question. However, antibiotics clearly have an important role in those with clinical signs of infection and delivery should not be delayed in these women. Detection of inflammation and potential therapies to modify the inflammatory response are currently only in the research stage but in the future may play a role in combination with amniocentesis to detect those pregnancies which may be compromised. As we have learnt from the ORACLE studies, ${ }^{52}$ any trial addressing outcome in pre-term birth must include robust long-term follow up of infants. Perceived short-term benefits in prolonging gestation may not translate to long-term benefit to children born as a result.

\section{REFERENCES}

1 Simhan HN, Canavan TP. Preterm premature rupture of membranes: diagnosis, evaluation and management strategies. BJOG 2005; 112: 32-37.

2 Wood NS, Costeloe K, Gibson AT, Hennessy EM, Marlow N, Wilkinson AR. The EPICure study: associations and antecedents of neurological and developmental disability at 30 months of age following extremely preterm birth. Arch Dis Child Fetal Neonatal Ed 2005; 90: 134-40.

3 Mangham LJ, Petrou S, Doyle LW, Draper ES, Marlow N. The Cost of Preterm Birth Throughout Childhood in England and Wales. Pediatr 2009; 123: e312-e27.

4 Artal R, Sokol RJ, Neuman M, Burstein AH, Stojkov J. Mechanical-properties of prematurely and nonprematurely ruptured membranes - methods and preliminary-results. Am J Obstet Gynecol 1976; 125: 655-59.

5 Moore RM, Mansour JM, Redline RW, Mercer BM, Moore JJ. The physiology of fetal membrane rupture: Insight gained from the determination of physical properties. Placenta 2006; 27: 1037-51.

6 Mclaren J, Malak TM, Bell SC. Structural characteristics of term human fetal membranes prior to labour: identification of an area of altered morphology overlying the cervix. Hum Reprod 1999; 14: 237-41.

7 Menon R, Fortunato SJ. Infection and the role of inflammation in preterm premature rupture of the membranes. Best Pract Res Clin Obstet Gynaecol. 2007; 21: 467-78.

8 Menon R, Fortunato SI. The role of matrix degrading enzymes and apoptosis in rupture of membranes. J Soc Gynecol Invest 2004; 11: 427-37.

9 Mazaki-Tovi S, Romero R, Kusanovic JP, Erez O, Pineles BL, Gotsch F, et al. Recurrent preterm birth. Semin Perinatol 2007; 31: 142-58.

10 Herbst A, Kallen K. Time between membrane rupture and delivery and septicemia in term neonates. Obstet Gynecol 2007; 110: 612-18.

11 Obi SN, Ozumba BC. Pre-term premature rupture of fetal membranes: The dilemma of management in a developing nation. J Obstet Gynaecol 2007; 27: 37-40.

12 Pasquier JC, Rabilloud M, Picaud JC, Claris O, Ecochard R, Moret S, et al. Modeling the duration of the latency period after preterm premature rupture of the membranes according to maternal and pregnancy characteristics: DOMINOS study. Eur J Obstet Gynecol Reprod Biol 2008; 139: 157-63.

13 Cotton DB HL, Strassner HT, Platt LD, Ledger WJ. Use of amniocentesis in preterm gestation with ruptured membranes. Obstet Gynecol 1984; 63: 10. 
14 Manuck TA, Maclean CC, Silver RM, Varner MW. Preterm premature rupture of membranes: does the duration of latency influence perinatal outcomes? Am J Obstet Gynecol 2009; 201: 414. e 1-6.

15 Fischer RL, Austin JD. Cervical length measurement by translabial sonography in women with preterm premature rupture of membranes: Can it be used to predict the latency period or peripartum maternal infection? J Matern Fetal Neonatal Med 2008; 21: 105-109.

16 Hong JS, Park KH, Noh JH, Suh YH. Cervical length and the risk of microbial invasion of the amniotic cavity in women with preterm premature rupture of membranes. J Korean Med Sci 2007; 22: 713-17.

17 Park JS, Yoon BH, Romero R, Bin Moon J, Oh SY, Kim JC, et al. The relationship between oligohydramnios and the onset of preterm labor in preterm premature rupture of membranes. Am J Obstet Gynecol 2001; 184: 459-62.

18 Mercer BM, Arheart KL. Antimicrobial therapy in expectant management of preterm premature rupture of the membranes. Lancet 1995; 346: 1271-279.

19 Kenyon S, Pike K, Jones DR, Brocklehurst P, Marlow N, Salt A et al. Childhood outcomes after prescription of antibiotics to pregnant women with preterm rupture of the membranes: 7-year followup of the ORACLE I trial. Lancet 2008; 372: 1310-108.

20 Prophylactic antibiotics for inhibiting preterm labour with intact membranes. Cochrane Database of Systematic Reviews 2002; CD000246 (Issue 3).

21 Kenyon S, Pike K, Jones DR, Brocklehurst P, Marlow N, Salt A, et al. Childhood outcomes after prescription of antibiotics to pregnant women with spontaneous preterm labour: 7-year follow-up of the ORACLE II trial. Lancet 2008; 372: 1319-27.

22 Garite TJ, Freeman RK, Linzey EM, Braly P. Use of amniocentesis in patients with premature rupture of membranes. Obstet Gynecol 1979; 54: 226-30.

23 Grenache DG, Gronowski AM. Fetal Lung Maturity. Clin Biochem 2006; 39: 1-10.

24 Averbuch B, Mazor M, Shohamvardi I, Chaim W, Vardi H, Horowitz S, et al. Intrauterine infection in women with preterm premature rupture of membranes - maternal and neonatal characteristics. Eur J Obstet Gynecol Reprod Biol 1995; 62: 25-29.

25 Goldenberg RL, Culhane JF, Iams JD, Romero R. Preterm birth 1 - Epidemiology and causes of preterm birth. Lancet 2008; 371: 75-84.

26 Yoon $\mathrm{BH}$, Park CW, Chaiworapongsa T. Intrauterine infection and the development of cerebral palsy. BJOG 2003; 110: 124-27.

27 Romero R, Yoon BH, Mazor M, Gomez R, Gonzalez R, Diamond MP, et al. A comparative-study of the diagnostic performance of amniotic-fluid glucose, white blood-cell count, interleukin-6, and gram stain in the detection of microbial invasion in patients with preterm premature rupture of membranes. Am I Obstet Gynecol 1993; 169: 839-51.

28 Romero R, Gomez R, Ghezzi F, Yoon BY, Mazor M, Edwin SS, et al. A fetal systemic inflammatory response is followed by the spontaneous onset of preterm parturition. Am J Obstet Gynecol 1998; 179: 186-93.

29 Gomez R, Romero R, Ghezzi F, Yoon BH, Mazor M, Berry SM. The fetal inflammatory response syndrome. Am J Obstet Gynecol 1998; 179: 194-202.

30 Yoon BH, Romero R, Moon JB, Shim SS, Kim M, Kim G, et al. Clinical significance of intra-amniotic inflammation in patients with preterm labor and intact membranes. Am J Obstet Gynecol 2001; 185: 1130-136.

31 Buhimschi IA, Zambrano E, Pettker CM, Bahtiyar MO, Paidas M, Rosenberg VA, et al. Using proteomic analysis of the human amniotic fluid to identify histologic chorioamnionitis. Obstet Gynecol 2008; 111: 403-12.

32 Maymon E, Romero R, Pacora P, Gomez R, Athayde N, Edwin S, et al. Human neutrophil collagenase (matrix metalloproteinase 8) in parturition, premature rupture of the membranes, and intrauterine infection. Am J Obstet Gynecol. 2000; 183: 94-99.

33 Maymon E, Romero R, Pacora P, Gervasi MT, Bianco K, Ghezzi F, et al. Evidence for the participation of interstitial collagenase (matrix metalloproteinase 1) in preterm premature rupture of membranes. Am I Obstet Gynecol 2000; 183: 914-20. 
34 Maymon E, Romero R, Pacora P, Gervasi MT, Edwin SS, Gomez R, et al. Matrilysin (matrix metalloproteinase 7) in parturition, premature rupture of membranes, and intrauterine infection. Am J Obstet Gynecol 2000; 182: 1545-551.

35 Kim KW, Romero R, Park HS, Park C-W, Shim S-S, Jun JK, et al. A rapid matrix metalloproteinase8 bedside test for the detection of intraamniotic inflammation in women with preterm premature rupture of membranes. Am J Obstet Gynecol 2007; 197: 292.e1-e5.

36 Nien JK, Yoon BH, Espinoza J, Kusanovic JP, Erez O, Soto E, et al. A rapid MMP-8 bedside test for the detection of intra-amniotic inflammation identifies patients at risk for imminent preterm delivery. Am J Obstet Gynecol 2006; 195: 1025-30.

37 Shim SS, Romero R, Hong JS, Park CW, Jun JK, Kim BI, et al. Clinical significance of intra-amniotic inflammation in patients with preterm premature rupture of membranes. Am J Obstet Gynecol 2004; 191: 1339-345.

38 Yoon BH, Romero R, Kim M, Kim EC, Kim T, Park JS, et al., editors. Clinical implications of detection of Ureaplasma urealyticum in the amniotic cavity with the polymerase chain reaction. 20th Annual Meeting of the Society-for-Maternal-Fetal-Medicine; 2000 Jan 31-Feb 05; Miami Beach, Florida. Mosby, Inc.

39 Porreco RP, Heyborne KD, Shapiro H. Amniocentesis in the management of preterm premature rupture of the membranes: A retrospective cohort analysis. J Mat Fetal Neonatal Med 2008; 21: 573-79.

40 Romero R, Quintero R, Oyarzun E, Wu YK, Sabo V, Mazor M, et al. Intraamniotic infection and the onset of labor in preterm premature rupture of the membranes. Am J Obstet Gynecol 1988; 159: 661-66.

41 Yeast JD, Garite TJ, Dorchester W. The risks of amniocentesis in the management of premature rupture of the membranes. Am J Obstet Gynecol 1984; 149: 505-508.

42 Gramellini D, Piantelli G, Di Marino O, Avanzini A, Vadora E. Amniotic fluid index variations after amniocentesis, amnioinfusion and amnioreduction: Preliminary data. Clin Exp Obstet Gynecol 1997; 24: 70-73.

43 Lacerte M, Bujold E, Audibert F, Mayrand M-H. Amniocentesis for PPROM management: a feasibility study. J Obstet Gynaecol Can 2008; 30: 659-64.

44 Gomez R, Romero R, Nien JK, Medina L, Carstens M, Kim YM, et al. Antibiotic administration to patients with preterm premature rupture of membranes does not eradicate intra-amniotic infection. J Mat Fetal Neonatal Med 2007; 20: 167-73.

45 Gotsch F, Romero R, Kusanovic JP, Mazaki-Tovi S, Pineles BL, Erez O, et al. The fetal inflammatory response syndrome. Clin Obstet Gynecol 2007; 50: 652-83.

46 Gravett MG, Adams KM, Sadowsky DW, Grosvenor AR, Witkin SS, Axthelm MK, et al. Immunomodulators plus antibiotics delay preterm delivery after experimental intraamniotic infection in a nonhuman primate model. Am J Obstet Gynecol. 2007; 197: 518. e1-8.

47 Markovitz BP, Goodman DM, Watson RS, Bertoch D, Zimmerman J. A retrospective cohort study of prognostic factors associated with outcome in pediatric severe sepsis: what is the role of steroids? Pediatr Crit Care Med 2005; 6: 270-74.

48 Ohlsson A, Lacy JB. Intravenous immunoglobulin for suspected or subsequently proven infection in neonates. Cochrane Database Syst Rev 2004 (1): CD001239.

49 Carr R, Modi N, Dore C. G-CSF and GM-CSF for treating or preventing neonatal infections. Cochrane Database Syst Rev 2003; 2003(3): CD003066.

50 Lauterbach R, Zembala M. Pentoxifylline reduces plasma tumour necrosis factor-alpha concentration in premature infants with sepsis. Eur J Pediatr 1996; 155: 404-409.

51 Lauterbach R, Pawlik D, Kowalczyk D, Ksycinski W, Helwich E, Zembala M. Effect of the immunomodulating agent, pentoxifylline, in the treatment of sepsis in prematurely delivered infants: A placebo-controlled, double-blind trial. Crit Care Med 1999; 27: 807-14.

52 Kenyon KP S, Jones DR, Brocklehurst P, Marlow N, Salt A, Taylor DJ. Childhood outcomes after prescription of antibiotics to pregnant women with spontaneous preterm labour: 7-year follow-up of the ORACLE II trial. Lancet 2008; 372: 1319-27. 